\title{
A LIST OF THE SPECIES OF CATOCALA TAKEN AT GROTON AND WINCHENDON, MASSACHUSETTS.
}

BY WILLIAM N. SOUTHER, GROTON, MASS.

The following list of species of the genus Catocala, have been taken in the vicinity of Groton and Winchendon, Mass. Those marked with an asterisk have been collected in both places, while Catocala minuta and C. briseis have only been found at Winchendon.

Catocala *nubilis $\mathrm{Hbn}$., June ro, quite common.

*amica Hbn., July 22, not common.

amica $\mathrm{Hbn}$., var. nerissa $\mathrm{Hy}$. Edw., July 24, not common.

* gracilis Edw., July 25, not common.

minuta Edw., August $\mathrm{x}$, rare.

* grynea Cram., August 3, common.

crataegi Saund., var. blandula Hulst, July 25 , quite common.

*ultronia, Hbn., July 20 , common.

coccinata Grt., July 24, not common.

* cerogama, Gn., August I9, not common.

* ilia Cram., July I 5 , common.

* ilia Cram., var. uxor Gn., July I 5, common.

illa Cram., var. zoe Behr. July 20 , rare.

*parta, Gn., July 2o, quite common.

*unijuga Wlk., August $\mathrm{x} 4$, quite common.

briseis Edw., August $\mathbf{I}$, not common.

* cara Gn., August 26, common.

* concumbens Wlk., August 20, common.

*amatrix Hbn., August 25 , not common.

*antinympha $\mathrm{Hbn}$., August 2, common.

badia G. and R., July 24 , rare.

*habilis Grt., August 25, common.

*paleogama Gn., August $\mathrm{4}$, common.

paleogama Gn. var. phalanga Grt., July 20 , rare.

*neogama S. and A., August 20 , rare.

*piatrix Grt., September I, quite common.

* relicta Wlk., August 25, not common.

* relicta Wlk., var. phrynia Hy. Edw., August 8, rare.

* relicta Wlk., var. bianca Hy. Edw., August 28, rare. 
epione Dru., July 26, common.

robinsonii Grt., August I8, rare.

retecta, Grt., August 20, common.

vidua, S. and A., August 25, common.

obscura Strck., July 7, August 18, rare.

*tristis Edw., August 8, rare. 

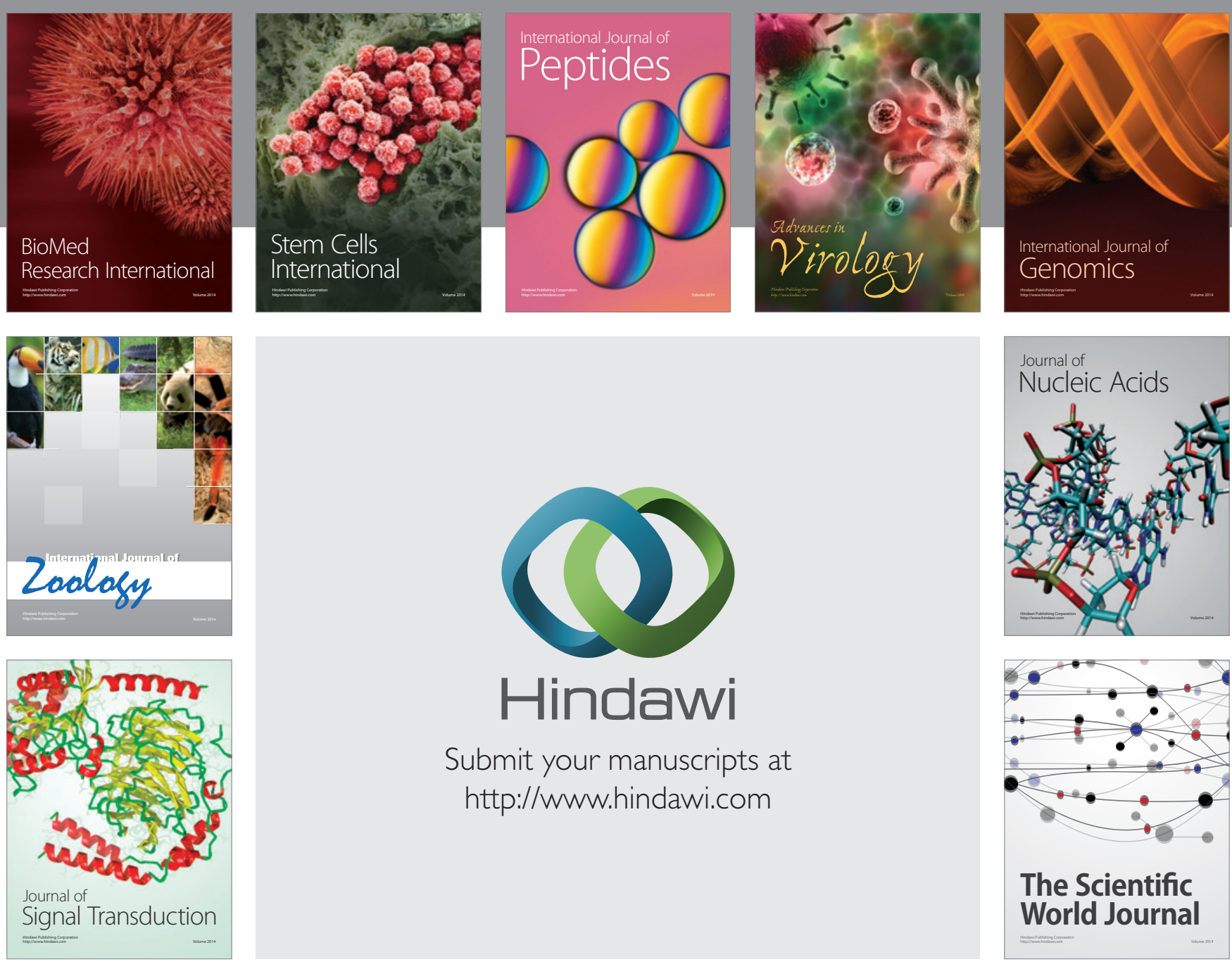

Submit your manuscripts at

http://www.hindawi.com
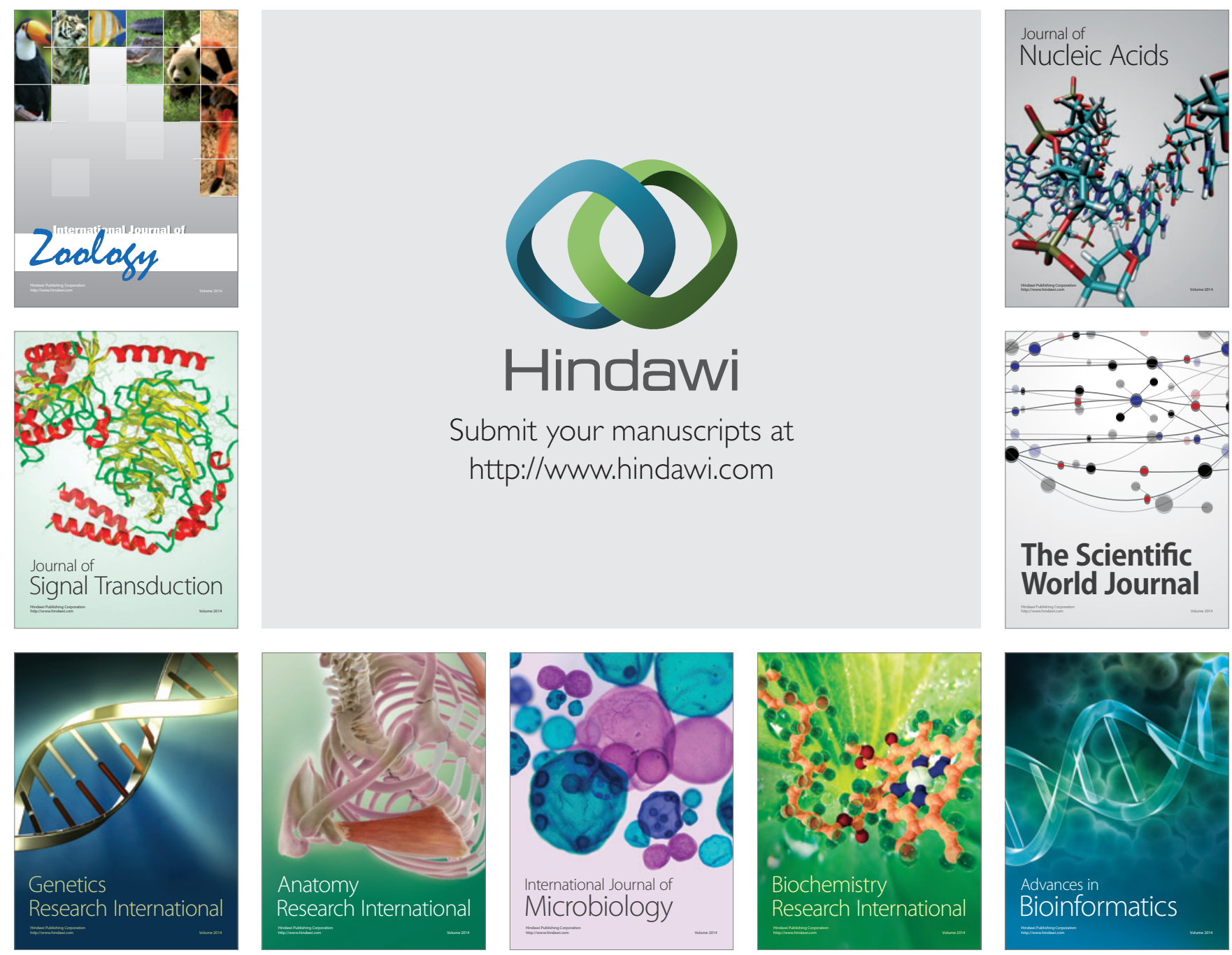

The Scientific World Journal
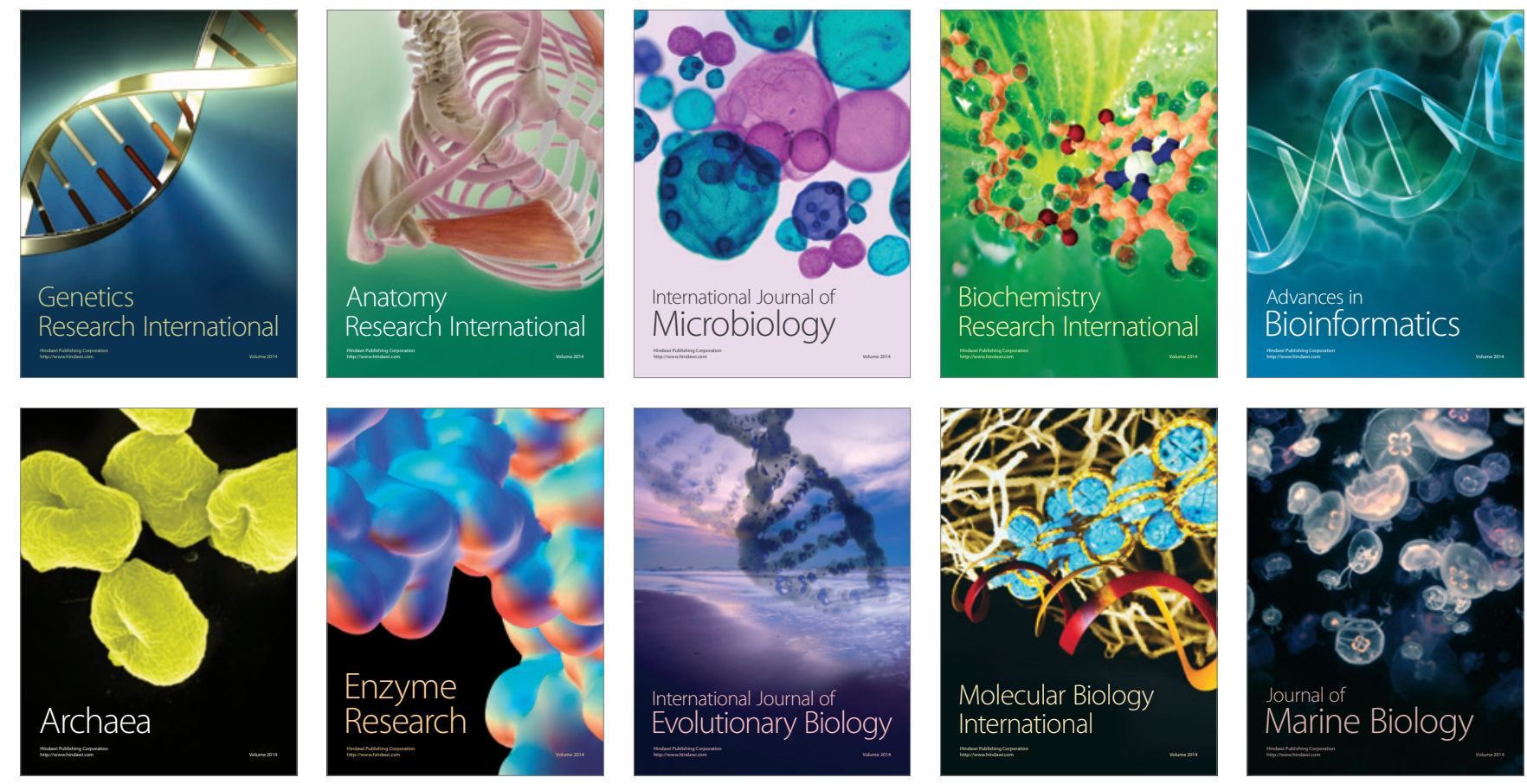